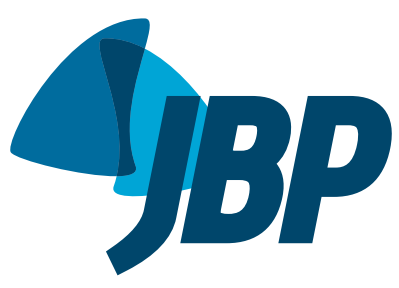

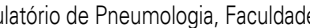
de Medicina, Universidade Tiradentes Aracaju (SE) Brasil.

2. Residência em Clínica Médica, Universidade Federal de Sergipe, Aracaju (SE) Brasil.

3. Residência em Anestesiologia. Hospital Universitário Professor Alberto Antunes, Universidade Federal de Alagoas, Maceió (AL) Brasil.

4. Faculdade de Medicina, Universidade Tiradentes, Aracaju (SE) Brasil.

a. (iD) http://orcid.org/0000-0001-7811-4305

b. (iD) http://orcid.org/0000-0002-2706-4018

c. (iD http://orcid.org/0000-0003-2667-9480

d. (iD http://orcid.org/0000-0002-8989-3444

Submitted: 25 July 2018

Accepted: 29 October 2018

Study carried out at Universidade Tiradentes, Aracaju (SE) Brasil.

\section{Evaluating the extremely elderly at a pulmonary function clinic for the diagnosis of respiratory disease: frequency and technical quality of spirometry}

\author{
Saulo Maia d'Avila Melo1,a, Larissa Alves de Oliveira2,b, \\ José Lucas Farias Wanderley ${ }^{3, c}$, Rodrigo dos Anjos Rocha ${ }^{4, d}$
}

\begin{abstract}
Objective: To determine the frequency of spirometry in elderly people, by age group, at a pulmonary function clinic, to assess the quality of spirometry in the extremely elderly, and to determine whether chronological age influences the quality of spirometry. Methods: This was a cross-sectional retrospective study evaluating information (spirometry findings and respiratory questionnaire results) obtained from the database of a pulmonary function clinic in the city of Aracaju, Brazil, for the period from January of 2012 to April of 2017. In the sample as a whole, we determined the total number of spirometry tests performed, and the frequency of the tests in individuals $\geq 60$ years of age, $\geq 65$ years of age, and by decade of age, from age 60 onward. In the extremely elderly, we evaluated the quality of spirometry using criteria of acceptability and reproducibility, as well as examining the variables that can influence that quality, such a cognitive deficit. Results: The sample comprised a total of 4,126 spirometry tests. Of those, 961 (23.30\%), 864 $(20.94 \%), 102(2.47 \%)$, and $26(0.63 \%)$ were performed in individuals $\geq 60, \geq 65, \geq$ 86 , and $\geq 90$ years of age (defined as extreme old age), respectively. In the extremely elderly, the criteria for acceptability and reproducibility were met in $88 \%$ and $60 \%$ of the spirometry tests (95\% Cl: $75.26-100.00$ and $40.80-79.20)$, respectively. The cognitive deficit had a negative effect on acceptability and reproducibility ( $p \leq 0.015$ and $p \leq$ 0.007 , respectively). Conclusions: A significant number of elderly individuals undergo spirometry, especially at $\geq 85$ years of age, and the majority of such individuals are able to perform the test in a satisfactory manner, despite their advanced age. However, a cognitive deficit could have a negative effect on the quality of spirometry.
\end{abstract}

Keywords: Spirometry; Aging; Aged, 80 and over.

\section{INTRODUCTION}

In Brazil and worldwide, the elderly population has grown because of decreased birth rates and a significantly increased lifespan. ${ }^{(1-3)}$ The elderly population is estimated to reach nearly 2 billion by 2050 , that is, it will represent approximately $22 \%$ of the world population. ${ }^{(1,4)}$ The World Health Organization defines elderly as persons $\geq 60$ years of age in developing countries, such as Brazil, and as persons $\geq 65$ years of age in developed countries. ${ }^{(1)}$ Aging can be classified into four stages: middle age (45-59 years); old age (60-74 years); old-old age (75-89 years); and extreme old age (90 years and over). ${ }^{(5)}$

The prevalence of respiratory diseases increases in the elderly population, and respiratory symptoms, such as cough and dyspnea, may be associated with non-respiratory comorbidities, such as heart diseases, muscle weakness, anemia, and lack of physical fitness, all of which may confuse the correct diagnosis. ${ }^{(6,7)}$ Spirometry is the most available and most widely used pulmonary function test in clinical practice, and it should be a part of the evaluation of patients with respiratory symptoms or suspected respiratory disease, as well as of the treatment follow-up of various respiratory diseases, especially obstructive diseases, such as asthma and COPD. ${ }^{(8-11)}$ However, spirometry is not routinely used by geriatricians, and most studies with spirometry involve a limited number of elderly individuals. ${ }^{(6,11-13)}$ The question remains, even among geriatricians, as to whether age is a limiting factor in the elderly's ability to perform spirometry in a satisfactory manner. $(6,12,14,15)$

The objective of the present study was to determine the frequency and proportion of spirometry in an elderly population, by age group, at a pulmonary function clinic. We also aimed to assess the quality of spirometry results in the extremely elderly and to determine whether chronological age influences the quality of spirometry.

\section{METHODS}

This was a cross-sectional retrospective study conducted at Universidade Tiradentes, located in the city of Aracaju, Brazil. The sample data (spirometry findings and respiratory questionnaire results) were obtained from the database of a pulmonary function clinic, located in 
Aracaju, for the period from January of 2012 to April of 2017. The study was approved by the Research Ethics Committee of Universidade Tiradentes (CAAE no. 67734717.2.0000.5371).

All spirometry tests were performed in the same room using the same spirometer with a pneumotachograph (Microlab 3500; Micro Medical Ltd., Rochester, England) connected to a computer where the spirometry data were stored. The stored data for each test were examined and evaluated individually regarding flow-volume and volume-time curves, as well as regarding conventional spirometric variables: FVC, FEV , FEV $_{1}$ /FVC ratio, PEF, and mid-expiratory flows, the results of which were expressed as liters and as a percentage of normal values according to the equations proposed by Crapo et al.(16) (for the population $\geq 87$ years of age) or the equations proposed by Pereira et al. ${ }^{(17)}$ (for the population $\leq 86$ years of age).

At least three curves were performed. Spirometry tests were performed in accordance with the technical standards and the acceptability and reproducibility criteria proposed by the Brazilian Thoracic Association, ${ }^{(10)}$ as were assessments of the quality of spirometry and spirometry interpretations. The same pulmonologist, who is certified in spirometry, interpreted the spirometry results.

Curves were accepted if they met the following criteria: abrupt start and absence of hesitation; a PEF variation of less than $10 \%$ of the highest PEF obtained or $0.5 \mathrm{~L} / \mathrm{s}$ (whichever was greater); a back-extrapolated volume of less than $5 \%$ of FVC or $150 \mathrm{~mL}$ (whichever was greater); a test duration of $6 \mathrm{~s}$ or an end-of-test plateau of $1 \mathrm{~s}$ on the volume-time curve; and no patient discomfort. In addition, cough in the first second of the maneuver, glottic closure, leak, and obstructed mouthpiece were criteria for rejection. ${ }^{(10,18)}$

The quality of spirometry was determined by assessing spirometry curves (flow-volume and volume-time curves), number of maneuvers performed, and values for spirometric variables. The quality of spirometry was graded as follows ${ }^{(10)}$ :

- A: at least two acceptable maneuvers in eight attempts, with the two highest FVC values and the two highest FEV values differing by $150 \mathrm{~mL}$ or less and with PEF being less than $10 \%$ or 500 $\mathrm{mL}$ (whichever was greater)

- B: at least two acceptable maneuvers with the two highest FVC values and the two highest FEV values being between 150 and $200 \mathrm{~mL}$ or with PEF being less than $15 \%$

- C: only one acceptable maneuver, or more than one acceptable maneuver, but with an FEV variation of more than $200 \mathrm{~mL}$

- D: no acceptable tests, no possibility of interpretation

The acceptability criteria included the parameters of quality $A, B$, and $C$ tests, and the reproducibility criteria included those of quality $A$ and $B$ tests.

The standardized respiratory questionnaire used in spirometry assessed demographic and anthropometric factors; respiratory symptoms; smoking status; comorbidities; history of lung and heart disease; occupational history; history of surgery and intubation; medications in use; clinical indication; and identification information of the physician who ordered the test. In the absence of adequate data on patient comorbidities from that respiratory questionnaire, attending physicians were asked to review medical records.

In order to statistically analyze the influence of comorbidities on the quality of spirometry, we subdivided comorbidities into five groups on the basis of the most impaired organ system: cognitive deficit; cerebrovascular disease without cognitive deficit; cardiovascular disease; lung disease; and others. Some patients belonged to more than one group because they had more than one type of comorbidity.

In the first phase of the study, we determined the total number of spirometry tests performed during the study period, regardless of patient chronological age, and the frequency of spirometry in individuals $\geq$ 60 years of age, in those $\geq 65$ years of age, and by decade of age, from age 60 onward. Subsequently, we determined the total number of individuals $\geq 86$ years, by gender, because the reference equation used to calculate the new values for forced spirometry in Brazil is limited to age $86 .^{(17)}$

In that first phase, we considered all spirometry tests performed, regardless of the fact that a given patient performed more than one test during the study period, taking only chronological age at the time of spirometry into account. In a second phase of the study, we selected and included patients $\geq 90$ years of age and excluded those $<90$ years of age. In order to assess the quality of spirometry, we considered only the first spirometry test performed by each patient.

Statistical analysis was performed with the IBM SPSS Statistics software package, version 21.0 (IBM Corporation, Armonk, NY, USA). Continuous variables were described as means and standard deviation, and categorical variables were expressed as absolute and relative frequencies. In order to determine whether demographic and comorbidity variables were significantly associated with the quality of spirometry, we used the chi-square test or Fisher's exact test to compare categorical data, and the Student's t-test for independent samples to compare numerical variables. The level of statistical significance was set at $p \leq 0.05$.

\section{RESULTS}

During the study period, a total of 4,126 spirometry tests were performed in individuals of various age groups (from 6 to 97 years of age). Of those tests, $961(23.30 \%)$ and $864(20.94 \%)$ were performed in individuals $\geq 60$ and $\geq 65$ years of age, respectively. Analysis by decade of age, from age 60 onward, revealed that 211 spirometry tests $(5.11 \%)$ were performed in individuals aged 60-69 years; 432 (10.47\%) were performed in those aged $70-79$ years; $292(7.08 \%)$ were performed in those aged $80-89$ years; and 26 
$(0.63 \%)$ were performed in those aged $\geq 90$ years In the sample as a whole, $102(2.47 \%)$ tests were performed in individuals $\geq 86$ years of age, of whom $67(1.62 \%)$ were women and $35(0.85 \%)$ were men (Figure 1).

When assessing the quality of the 26 spirometry tests of individuals $\geq 90$ years of age (defined as extreme old age), we excluded 1 because it belonged to a patient who performed 2 tests, that is, we selected for the study the spirometry tests of 25 patients who were aged 90-97 years, mean age of $92.12 \pm 2.22$ years (95\% CI: $91.20-93.04)$, and were predominantly female $(18 / 25 ; 72 \%)$.

Table 1 presents the demographic and anthropometric characteristics, comorbidities, and smoking status of the patients $\geq 90$ years of age $(n=25)$. Some patients had one or more comorbidities. Patient distribution by comorbidity group was as follows: 10 patients with lung disease ( 7 with asthma, 4 with COPD, and 1 with asthma and COPD); 17 patients with cardiovascular

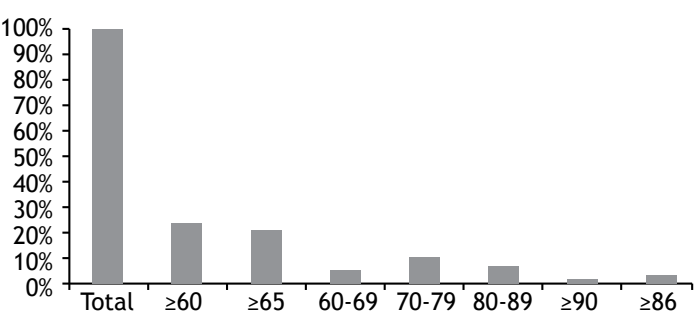

Figure 1. Distribution of spirometry tests $(N=4,126)$ performed during the study period, by age group. disease (systemic arterial hypertension, arrhythmias, and/or dyslipidemia); 4 patients with cerebrovascular disease without cognitive deficit (stroke sequela); 7 patients with cerebrovascular disease with cognitive deficit (Alzheimer's disease and other dementia); and 5 patients with other comorbidities (hypothyroidism, hearing deficit, diabetes mellitus, anxiety, and/ or depression). For those 25 patients, spirometry was ordered by pulmonologists, in 21 (84\%); by cardiologists, in $3(12 \%)$; and by general practitioners, in 1 (4\%; Figure 2).

The acceptability criteria were met in 22 of the 25 spirometry tests (88\%; 95\% CI: 75.26-100.00), with 13 tests being graded quality A $(52 \% ; 95 \% \mathrm{CI}$ : $32.42-71.58) ; 2$ being graded quality $\mathrm{B}(8 \% ; 95 \% \mathrm{CI}$ : $0.00-18.63) ; 7$ being graded quality C (28\%; $95 \% \mathrm{CI}$ : $10.40-45.60)$; and 3 being graded quality D (12\%; $95 \%$ CI: $0.00-24.74$; Figure 3 and 4). The reproducibility criteria were met in 15 of the 25 spirometry tests $(60 \%$; quality $A$ and $B$ tests; $95 \% \mathrm{CI}: 40.80-79.20)$ and were not met in 10 (40\%; quality $C$ and D tests; Figure 4).

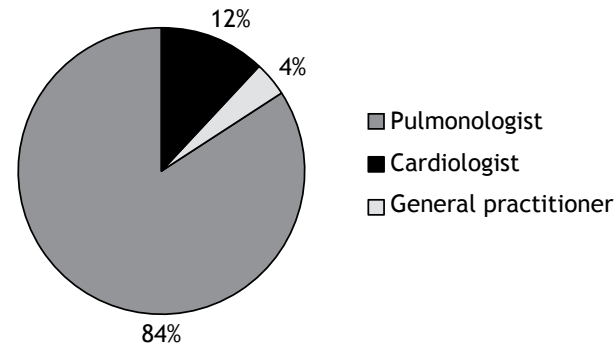

Figure 2. Specialty of the physician who ordered spirometry for individuals $\geq 90$ years of age.

Table 1. Demographic and anthropometric characteristics, smoking status, and comorbidities in individuals $\geq 90$ years of age. ${ }^{\mathrm{a}}$

\begin{tabular}{|c|c|c|}
\hline Variable & $\begin{array}{c}\text { Age } \geq 90 \text { years } \\
(n=25)\end{array}$ & $95 \% \mathrm{Cl}$ \\
\hline Female gender & $18(72)$ & \\
\hline Age, years & $92.12 \pm 2.22$ & $91.2-93.04$ \\
\hline Height, m & $1.48 \pm 0.07$ & $1.45-1.51$ \\
\hline $\mathrm{BMI}, \mathrm{kg} / \mathrm{m}^{2}$ & $27.74 \pm 5.46$ & $25.49-30.00$ \\
\hline Weight, kg & $60.64 \pm 10.92$ & $56.13-65.15$ \\
\hline \multicolumn{3}{|l|}{ Smoking status } \\
\hline Nonsmoker & $21(84)$ & \\
\hline Former smoker & $3(12)$ & \\
\hline Smoker & $1(4)$ & \\
\hline \multicolumn{3}{|l|}{ Comorbidities $^{b}$} \\
\hline Asthma & $7(28)$ & \\
\hline COPD & $4(16)$ & \\
\hline SAH & $14(56)$ & \\
\hline Dyslipidemia & $7(28)$ & \\
\hline OSA & $5(20)$ & \\
\hline Cardiac arrhythmia & $4(16)$ & \\
\hline Cerebrovascular disease & $4(16)$ & \\
\hline Cognitive deficit & $7(28)$ & \\
\hline Other comorbidities ${ }^{c}$ & $5(20)$ & \\
\hline
\end{tabular}

BMI: body mass index; SAH: systemic arterial hypertension; and OSA: obstructive sleep apnea. ${ }^{\text {a Values expressed }}$ as $\mathrm{n}(\%)$ or as mean $\pm \mathrm{SD}$. ' Some patients had one or more comorbidities. ${ }^{\mathrm{C}}$ Hypothyroidism, hearing deficit, diabetes mellitus, anxiety, and/or depression. 


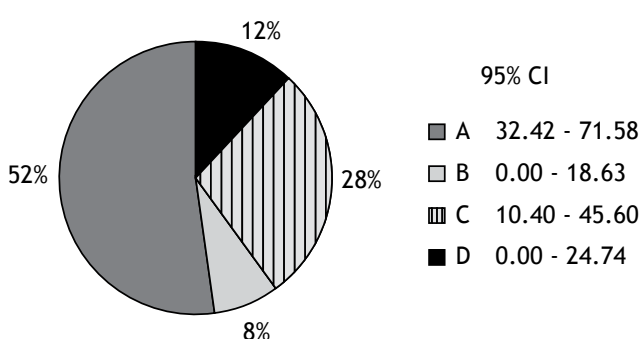

Figure 3. Spirometry quality grading in individuals $\geq$ 90 years of age. Adapted from the Brazilian Thoracic Association. ${ }^{(10)}$

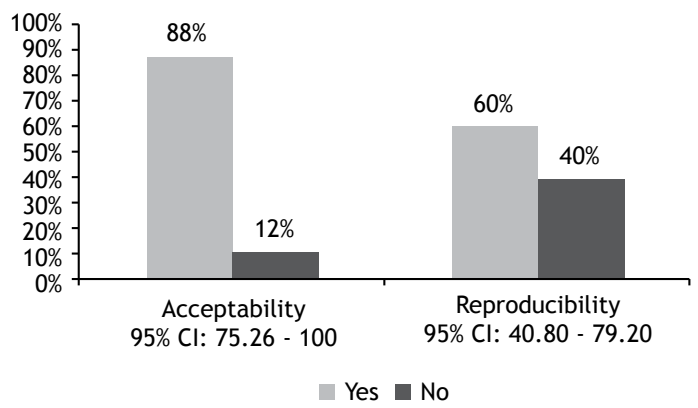

Figure 4. Acceptability and reproducibility of spirometry in individuals $\geq 90$ years of age. Adapted from the Brazilian Thoracic Association. ${ }^{(10)}$

The spirometry tests that met the acceptability criteria (quality A, B, and C tests) were eligible for interpretation. The most common errors that had a negative effect on the quality (acceptability and/ or reproducibility) of spirometry were as follows: submaximal effort, in 14 tests (56\%); expiratory time of $<3 \mathrm{~s}$ and no plateau in the last second, in $7(28 \%)$; no plateau in the last second, in $7(28 \%)$; abrupt termination of expiration, in $7(28 \%)$; cough, in $9(36 \%)$; and leak, in $3(12 \%)$. Some spirometry tests had more than one error, which explains why the total proportion of errors was greater than $100 \%$.

The variables gender, age, body mass index (BMI), and comorbidity group were not found to influence the quality of spirometry, except for cognitive deficit, which had a negative effect on the quality of spirometry in terms of acceptability and reproducibility ( $p \leq 0.015$ and $p \leq 0.007$, respectively), whereas lung disease showed the highest reproducibility ( $p \leq 0.018$ ). The other variables (gender, age, and BMI) showed no significant differences (Table 2).

\section{DISCUSSION}

The elderly population is growing substantially worldwide. $^{(1)}$ By 2025, Brazil will rank 6th among the countries with the greatest number of elderly individuals in the world, with a high proportion of extremely elderly individuals (from 394,000 in 2010 to an estimated nearly 3.5 million in 2050). ${ }^{(3)}$

Although spirometry is practical and important to assessing pulmonary function, there have been few studies involving the elderly. ${ }^{(11)}$ In the present study, we found that a significant number of elderly individuals attended the pulmonary function clinic on an outpatient basis. Of all spirometry tests performed, 961 (23.30\%) were performed in individuals $\geq 60$ years of age, 864 $(20.94 \%)$ were performed in individuals $\geq 65$ years of age, and 102 (2.47\%) were performed in individuals $\geq 86$ years of age.

When we analyzed reference equations for spirometry all over the world, we found few data on the elderly, and the existing data are based on relatively small, non-representative samples. ${ }^{(11,19-24)}$ In Brazil, the equations proposed by Pereira et al.(17) in 2007 were derived in a sample of men and women up to 86 and 85 years of age, respectively, with a small number of patients over 75 years of age. In 2017, Rufino et al. (22) included patients up to 80 years of age in their sample, claiming that the average life expectancy in Brazil was 74 years. In 2012, the Global Lung Function Initiative, ${ }^{(11)}$ endorsed by the European Respiratory Society, carried out a study that presented multi-ethnic reference equations for spirometry on the basis of 97,759 records of individuals who were aged 3-95 years (females, 55.3\%) from 33 countries in five continents. In that sample, $0.8 \%$ of the individuals were $\geq 80$ years of age, $0.24 \%$ were $>85$ years of age, and only $0.035 \%$ were $>90$ years of age. Those authors underscore the limitations of the predicted values for individuals $>75$ years of age and suggest that these values be interpreted with caution. ${ }^{(11)}$

Given the estimated increasing number of extremely elderly individuals in the coming decades, the extremely elderly represent a specific group and a new challenge requiring study from a health standpoint, especially with regard to the respiratory system. We showed that $26(0.63 \%)$ of the spirometry tests in our sample were performed in extremely elderly individuals, most of whom were women (72\%). We found no previous research focusing exclusively on the extremely elderly, and existing studies on the elderly do not specify how many patients were over 90 years of age, making a proper comparison between those studies and ours difficult. ${ }^{(6,12-15,23,24)}$

Aging is accompanied by changes in all organ systems, either due to senescence or to the presence of a larger number of comorbidities. For this reason, the ability of elderly individuals to understand the phases of spirometry, coordinate their performance, and make the effort required to obtain reliable measures is questionable. ${ }^{(6,24,25)}$ Approximately $15 \%$ of elderly individuals will not cooperate in performing spirometry. ${ }^{(10)}$ Spirometry is not routinely used by geriatricians because the question remains as to whether age would be a limiting factor to performing spirometry adequately. ${ }^{(6,12,15)}$

Our study underscores the fact that spirometry was ordered basically by pulmonologists and cardiologists, although the patients in our sample were followed by geriatricians. This agrees with data in the literature that indicate that spirometry is not widely used in 
Table 2. Determination of variables that can influence the acceptability and reproducibility of spirometry in the extremely elderly. ${ }^{a, b}$

\begin{tabular}{|c|c|c|c|c|c|c|}
\hline \multirow[t]{3}{*}{ Variable } & \multicolumn{3}{|c|}{ Acceptability criteria } & \multicolumn{3}{|c|}{ Reproducibility criteria } \\
\hline & $\mathrm{ABC}$ & D & p & AB & CD & $\mathbf{p}$ \\
\hline & $(n=22)$ & $(n=3)$ & & $(n=15)$ & $(n=10)$ & \\
\hline Female gender & $16(72.7)$ & $2(66.7)$ & & $10(66.7)$ & $8(80.0)$ & \\
\hline \multicolumn{7}{|l|}{ Comorbidity group c,* } \\
\hline Lung disease & $10(45.5)$ & $0(0.0)$ & 0.250 & $9(60.0)$ & $1(10.0)$ & 0.018 \\
\hline Cardiovascular disease & $16(72.7)$ & $1(33.3)$ & 0.230 & $10(66.7)$ & $7(70.0)$ & 0.230 \\
\hline Cognitive deficit & $4(18.2)$ & $3(100.0)$ & 0.015 & $1(6.7)$ & $6(60.0)$ & 0.007 \\
\hline Cerebrovascular disease & $3(13.6)$ & $1(33.3)$ & 0.422 & $1(6.7)$ & $3(30.0)$ & 0.267 \\
\hline Others $^{\mathrm{d}}$ & $5(22.7)$ & $0(0.0)$ & 1.000 & $4(26.7)$ & $1(10.0)$ & 0.615 \\
\hline Age $^{* *}$ & $91.86 \pm 2.17$ & $94.00 \pm 2.00$ & 0.120 & $92.20 \pm 2.43$ & $92.00 \pm 2.00$ & 0.831 \\
\hline $\mathrm{BMI}^{* *}$ & $27.80 \pm 5.74$ & $27.33 \pm 3.44$ & 0.890 & $28.21 \pm 6.41$ & $27.04 \pm 3.83$ & 0.608 \\
\hline
\end{tabular}

IMC: body mass index. ${ }^{a}$ Adapted from the Brazilian Thoracic Association. (10) bValues expressed as $\mathrm{n}$ (\%) or as mean \pm SD. 'Some patients had one or more comorbidities. dHypothyroidism, hearing deficit, diabetes mellitus, anxiety, and/or depression. *Fisher's exact test.**Student's t-test for independent samples.

geriatric practice, which leads to a limited number of spirometry results.

Our results showed that the criteria for acceptability and reproducibility were met in $88 \%$ and $60 \%$ of the spirometry tests, respectively, and that only $12 \%$ of the tests were excluded because of poor technique, which was significantly correlated with cognitive deficit. We also showed that age, gender, BMI, and comorbidities other than cognitive deficit did not interfere with the quality of spirometry.

A study ${ }^{(6)}$ conducted with a sample of 715 individuals $\geq$ 65 years of age reported that $81.50 \%$ of the spirometry tests were accepted and $18.2 \%$ were excluded because of poor technique. Age, BMI, and presence of depression did not influence the quality of the test; however, cognitive impairment and a low level of education had a negative effect on the quality of spirometry.

Sherman et al.(12) evaluated 65 individuals $\geq 65$ years of age (mean age, 75 years) and reported that 8 individuals $(12.3 \%)$ were unable to perform spirometry and $18(31.6 \%)$ did not meet the reproducibility criteria. Those authors suggest that the vast majority of elderly individuals are able to perform spirometry with adequate technique, and that elderly individuals who are unable to perform it may have impaired cognitive function.

A retrospective study ${ }^{(14)}$ that assessed the quality of spirometry and DLCO testing by comparing 150 individuals $\geq 80$ years of age (elderly group) with 178 adults aged $40-50$ years (control group) reported that $139(92.6 \%)$ of the elderly group and $163(91.5 \%)$ of the control group spirometry tests met all acceptability and reproducibility criteria.
A study of elderly individuals $\geq 65$ years of age who had obstructive disease (asthma and/or COPD) reported that cognitive impairment, shorter six-minute walk distances, and lower levels of education were independent risk factors for lower spirometry acceptability rates, whereas male gender and age were risk factors for poorer reproducibility of $\mathrm{FEV}_{1}{ }^{\left({ }^{(15)}\right.}$ In addition, previous studies that used the Mini-Mental State Examination have shown that cognitive deficit has a negative effect on the quality of spirometry. ${ }^{(13,26)}$ The findings of the aforementioned studies are in agreement with those of our research, which showed that cognitive deficit had a negative effect on performing spirometry, and that chronological age did not interfere with the quality of spirometry. Chronological age does not always correspond to biological age; therefore, we must encourage active and healthy aging.

The limitations of the present study include the fact that it was a retrospective study and that the Mini-Mental State Examination was not used to assess the degree of cognitive deficit.

In conclusion, the present study calls attention to the fact that currently a significant number of elderly individuals undergo spirometry, especially at $\geq 85$ years of age, and that the majority of such individuals are able to perform the test in a satisfactory manner. Age does not seem to be a limiting factor to performing spirometry, nor does extreme old age influence the quality of the test. However, cognitive deficit has a negative effect on the quality of spirometry. Therefore, spirometry can and should be used as a test to assess and control respiratory diseases in the extremely elderly, and its use should be disseminated and encouraged in geriatric practice.

\section{REFERENCES}

World Health Organization [homepage on the Internet]. Geneva: World Health Organization [updated 2002 Apr; cited 2017 Jun 17]. Active ageing: a policy framework. Available from: http://www.who. int/ageing/publications/active_ageing/en/

2. de Carvalho JA, Garcia RA. The aging process in the Brazilian population: a demographic approach [Article in Portuguese]. Cad Saude Publica. 2003;19(3):725-33. https://doi.org/10.1590/S0102 $311 \times 2003000300005$ 
3. Instituto Brasileiro de Geografia e Estatística (IBGE) [homepage on the Internet]. Rio de Janeiro: IBGE; [cited 2017 Mar 22]. Projeção da População do Brasil por sexo e idade: 2000-2060. Available from: http://www.ibge.gov.br/home/estatistica/populacao/projecao_da_ populacao/2013/default tab.shtm

4. United Nations. Department of Economic and Social Affairs [homepage on the Internet]. New York City: UN; cited 2017 Feb 25]. World Population Prospects. The 2010 Revision, Volume I: Comprehensive Tables. [Adobe Acrobat document, 503p.] Available from: http://www.un.org/en/development/desa/ population/publications/pdf/trends/WPP2010/WPP2010_Volume-I_ Comprehensive-Tables.pdf

5. Lauretti GR, Mattos AL. Fourth age and extreme old age: replacement of polypharmacy by a controlled-release hydromorphone tablet to control chronic pain. Rev Dor. 2011;12(3):235-9. https://doi. org/10.1590/S1806-00132011000300008

6. Pezzoli L, Giardini G, Consonni S, Dallera I, Bilotta C, Ferrario G, et al. Quality of spirometric performance in older people. Age Ageing 2003;32(1):43-6. https://doi.org/10.1093/ageing/32.1.43

7. Akgün K M, Crothers K, Pisani M. Epidemiology and Management of Common Pulmonary Diseases in Older Persons. J Gerontol A Biol Sci Med Sci. 2012;67(3):276-91. https://doi.org/10.1093/gerona/g|r251

8. Global Initiative for Asthma (GINA) homepage on the Internet]. Bethesda: GINA [cited 2018 Jun 30]. Global Strategy for Asthma Management and Prevention, 2018. Available from: https:// ginasthma.org/2018-gina-report-global-strategy-for-asthmamanagement-and-prevention/

9. Global Initiative for Chronic Obstructive Lung Disease (GOLD [homepage on the Internet]. Bethesda: GOLD [cited 2018 Jun 30]. Global Strategy for the Diagnosis, Management and Prevention of COPD 2018. Available from: https://goldcopd.org/wp-content/../ GOLD-2018-v6.0-FINAL-revised-20-Nov_WMS.pd

10. Sociedade Brasileira de Pneumologia e Tisiologia. Diretrizes para Testes de Função Pulmonar. J Pneumol. 2002;28(Suppl 3):S1-S238.

11. Quanjer PH, Stanojevic S, Cole TJ, Baur X, Hall GL, Culver BH, et al. Multi-ethnic reference values for spirometry for the $3-95-y r$ age range: the global lung function 2012 equations. Eur Respir J. 2012;40(6):1324-43. https://doi.org/10.1183/09031936.00080312

12. Sherman CB, Kern D, Richardson ER, Hubert M, Fogel BS. Cognitive function and spirometry performance in the elderly. Am Rev Respir Dis. 1993;148(1):123-6. https://doi.org/10.1164/ajrccm/148.1.123

13. Carvalhaes-Neto N, Lorino H, Gallinari C, Escolano S, Mallet A, Zerah $\mathrm{F}$, et al. Cognitive function and assessment of lung function in the elderly. Am J Respir Crit Care Med. 1995:152(5 Pt 1):1611-5. https:// doi.org/10.1164/ajrccm.152.5.7582303

14. Haynes JM. Pulmonary function test quality in the elderly: comparison with younger adults. Respir Care. 2014;59(1):16-21. https://doi.org/10.4187/respcare.02331

15. Bellia V, Pistelli R, Catalano F, Antonelli-Incalzi R, Grassi V, Melillo G, et al. Quality control of spirometry in the elderly. The SA.R.A. study. SAlute Respiration nell'Anziano = Respiratory Health in the Elderly Am J Respir Crit Care Med. 2000;161(4 Pt 1):1094-100. https://doi. org/10.1164/ajrccm.161.4.9810093

16. Crapo RO, Morris AH, Gardner RM. Reference spirometric values using techniques and equipment that meet ATS recommendations. Am Rev Respir Dis. 1981;123(6):659-64.

17. Pereira CA, Sato T, Rodrigues SC. New reference values for forced spirometry in white adults in Brazil. J Bras Pneumol. 2007;33(4):397406. https://doi.org/10.1590/S1806-37132007000400008

18. Miller MR, Crapo R, Hankinson J, Brusasco V, Burgos F, Casaburi R et al. General considerations for lung function testing. Eur Respir J. 2005;26(1):153-61. https://doi.org/10.1183/09031936.05.00034505

19. Quanjer PH, Tammeling GJ, Cotes JE, Pedersen OF, Peslin R, Yernault JC. Lung volumes and forced ventilatory flows. Report Working Party Standardization of Lung Function Tests, European Community for Steel and Coal. Official Statement of the European Respiratory Society. Eur Respir J Suppl. 1993;16:5-40. https://doi. org/10.1183/09041950.005s1693

20. Knudson RJ, Lebowitz MD, Holberg CJ, Burrows B. Changes in the normal maximal expiratory flow-volume curve with growth and aging. Am Rev Respir Dis. 1983;127(6):725-34

21. Hankinson JL, Odencrantz JR, Fedan KB. Spirometric reference values from a sample of the general U.S. population. Am J Respir Crit Care Med. 1999;159(1):179-87. https://doi.org/10.1164/ ajrccm.159.1.9712108

22. Rufino R, Costa CH, Lopes AJ, Maiworm Al, Maynard K, Silva LM et al. Spirometry reference values in the Brazilian population. Braz J Med Biol Res. 2017:50(3):e5700. https://doi.org/10.1590/1414$431 \times 20175700$

23. Burr ML, Phillips KM, Hurst DN. Lung function in the elderly. Thorax. 1985;40(1):54-9. https://doi.org/10.1136/thx.40.1.54

24. Czajkowska-Malinowska M, Tomalak W, Radliński J. Quality of spirometry in the elderly. Pneumonol Alergol Pol. 2013;81(6):511-7.

25. Turkeshi E, Zelenukha D, Vaes B, Andreeva E, Frolova E, Degryse JM Predictors of poor-quality spirometry in two cohorts of older adults in Russia and Belgium: a cross-sectional study. NPJ Prim Care Respir Med. 2015;25:15048. https://doi.org/10.1038/npjpcrm.2015.48

26. Allen $S$, Yeung $P$, Janczewski M, Siddique N. Predicting inadequate spirometry technique and the use of $\mathrm{FEV} 1 / \mathrm{FEV} 3$ as an alternative to FEV1/FVC for patients with mild cognitive impairment. Clin Respir J. 2008;2(4):208-13. https://doi.org/10.1111/.1752-699X.2008.00063.x 